\title{
Acute pulmonary edema secondary to upper airway obstruction by bilateral vocal cord paralysis after total thyroidectomy -A case report-
}

\author{
Won Ho Kim ${ }^{1}$, and Seung A Ryu ${ }^{2}$ \\ Department of Anesthesiology and Pain Medicine, ${ }^{1}$ Samsung Medical Center, Sungkyunkwan University School of Medicine, \\ ${ }^{2}$ Seoul Medical Center, Seoul, Korea
}

This paper reports the case of a 65-year-old woman with a history of mild arterial hypertension who presented with acute pulmonary edema immediately after a total thyroidectomy. The edema was found to have been caused by an acute upper airway obstruction secondary to bilateral vocal cord paralysis. Her pulmonary edema resolved with treatment including reintubation, mechanical ventilation with positive end-expiratory pressure, diuretics, morphine, and fluid restriction. This report discusses the possible pathogenesis of this rare clinical situation. This case highlights the possibility of an acute upper airway obstruction caused by bilateral vocal cord paralysis after a total thyroidectomy and the need for prompt treatment to prevent the development of pulmonary edema. (Korean J Anesthesiol 2012; 62: 387-390)

Key Words: Acute upper airway obstruction, Pulmonary edema, Recurrent laryngeal nerve injury, Thyroidectomy, Vocal cord paralysis.

Negative pressure pulmonary edema secondary to an acute upper airway obstruction has been reported in several clinical situations. The most common cause of an acute upper airway obstruction associated with anesthesia is a laryngospasm after extubation [1]. A markedly negative intrathoracic pressure that develops with an increased inspiratory effort can cause pulmonary edema [2]. We encountered a rare case of pulmonary edema that developed immediately after a total thyroidectomy due to an acute upper airway obstruction secondary to vocal cord paralysis. Initially, We did not know the underlying cause of pulmonary edema, and her pulmonary edema was managed conservatively [3]. This case should remind clinicians of the serious consequences of a recurrent laryngeal nerve injury as a complication of total thyroidectomy. It also highlights the need for a careful physical examination immediately after a thyroidectomy. We report this case with a review of the relevant literature.

Received: December 22, 2010. Revised: 1st, March 4, 2011; 2nd, May 1, 2011; 3rd, May 4, 2011. Accepted: May 6, 2011.

Corresponding author: Won Ho Kim, M.D., Department of Anesthesiology and Pain Medicine, Samsung Medical Center, Sungkyunkwan University School of Medicine, 50, Irwon-dong, Gangnam-gu, Seoul 135-710, Korea. Tel: 82-2-3410-2470, Fax: 82-2-3410-0360, E-mail: bullet57@naver.com (c) This is an open-access article distributed under the terms of the Creative Commons Attribution Non-Commercial License (http:// creativecommons.org/licenses/by-nc/3.0/), which permits unrestricted non-commercial use, distribution, and reproduction in any medium, provided the original work is properly cited. 


\section{Case Report}

A 65-year-old woman (weight, $44 \mathrm{~kg}$; height, $153 \mathrm{~cm}$ ) was admitted to our hospital for an elective total thyroidectomy. She had been diagnosed with a papillary carcinoma of the thyroid. Her medical history included hypertension, minor depression, a cerebral infarction, and brain surgery. Her medications included aspirin, a calcium channel blocker, and antidepressant. The preoperative chest radiograph and electrocardiography revealed no abnormalities. Echocardiography revealed mild pulmonary hypertension. The blood tests were within the normal limits.

Her blood pressure, heart rate and $\mathrm{SpO}_{2}$ was 140/70 mmHg, 80 beats/min and $99 \%$, respectively. General anesthesia was induced with thiopental $5 \mathrm{mg} / \mathrm{kg}$ and rocuronium $0.6 \mathrm{mg} /$ $\mathrm{kg}$. She was intubated without problems using a $7.0 \mathrm{~mm}$ oral endotracheal tube that was fixed $22 \mathrm{~cm}$ from the mouth. Anesthesia was maintained with air $1 \mathrm{~L} / \mathrm{min}, \mathrm{O}_{2} 1 \mathrm{~L} / \mathrm{min}$, sevoflurane $1-2 \mathrm{vol} \%$ and a continuous infusion of remifentanil $0.01-0.05 \mu \mathrm{g} / \mathrm{kg} / \mathrm{min}$. Her vital signs, airway pressures, and end-tidal $\mathrm{CO}_{2}$ remained stable during surgery. The planned surgical procedure was performed uneventfully in 2 hours and 55 minutes. A total volume of $900 \mathrm{ml}$ lactated Ringer's solution was administered. During surgery, the estimated blood loss was $200 \mathrm{ml}$ and urine output was $300 \mathrm{ml}$. After reversing the muscle relaxant, the patient was extubated in the operating room after confirming her ability to obey commands and her full recovery of motor function as tested by the hand grip and head control.

On the way to the post-anesthesia care unit, the patient

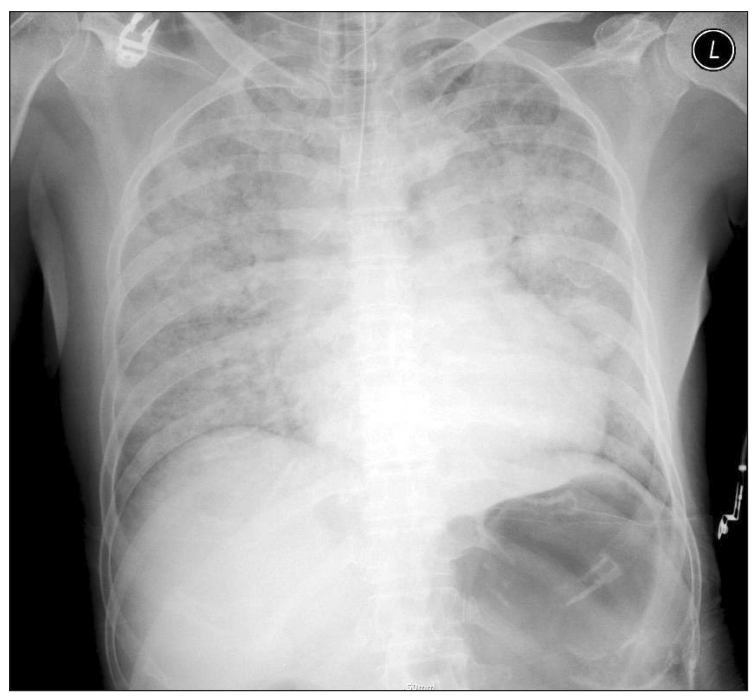

Fig. 1. Portable chest radiograph taken in the postoperative recovery room, revealing diffuse, bilateral, hazy, and interstitial opacity throughout bilateral lung field, with a slightly increased heart size, and no pleural effusion. was unable to breath and became cyanotic. The initial blood pressure at the recovery room was $110 / 60 \mathrm{mmHg}$, heart rate was 90 beats/min, and $\mathrm{SpO}_{2}$ was $78 \%$. The oral airway was maintained and manual bagging was started with $100 \%$ oxygen at $10 \mathrm{~L} / \mathrm{min}$ but there was considerable resistance and adequate oxygenation could not be maintained. A decision was made to reintubate the patient with midazolam $2 \mathrm{mg}$ and succinylcholine $2 \mathrm{mg} / \mathrm{kg}$ while inserting an arterial line catheter into the left radial artery. Direct laryngoscopy revealed no specific abnormalities, such as laryngeal edema or aspirate. The patient was intubated successfully with a 7.0-mm endotracheal tube and ventilated several times with a bag valve mask with less resistance. However, a large volume of pink, frothy fluid emerged from the endotracheal tube, prompting an interim diagnosis of pulmonary edema. Pulmonary auscultation revealed moist rales in the entire bilateral lung fields. Despite the continued manual ventilation and tracheal suction with $100 \% \mathrm{O}_{2}$, the $\mathrm{SpO}_{2}$ remained at approximately $80 \%$. The first arterial blood gas analysis was as follows: $\mathrm{pH} 7.40, \mathrm{PaCO}_{2} 30.4$ mmHg, $\mathrm{PaO}_{2} 35.0 \mathrm{mmHg}, \mathrm{SaO}_{2} 66.8 \%$ at $\mathrm{FiO}_{2}$ 1.0. A portable chest radiograph confirmed the typical pattern of pulmonary edema with symmetric bilateral infiltrates and a slightly enlarged heart (Fig. 1). As a treatment of pulmonary edema, morphine $3 \mathrm{mg}$ and furosemide $20 \mathrm{mg}$ were administered. After 10 minutes, spontaneous respiration was observed and the patient could reply to verbal commands.

The patient was transferred to the ICU for ventilatory support with a positive end-expiratory pressure (PEEP) of $7 \mathrm{~cm} \mathrm{H}_{2} \mathrm{O}$. The patient's $\mathrm{SpO}_{2}$ remained $>97 \%$ on $100 \%$ oxygen. The follow-up arterial blood gas analysis was as follows: $\mathrm{pH}$ 7.39, $\mathrm{PaCO}_{2} 33.6$ mmHg, $\mathrm{PaO}_{2} 125 \mathrm{mmHg}, \mathrm{SaO}_{2} 98.9 \%$ at $\mathrm{FiO}_{2}$ 1.0. The cardiac

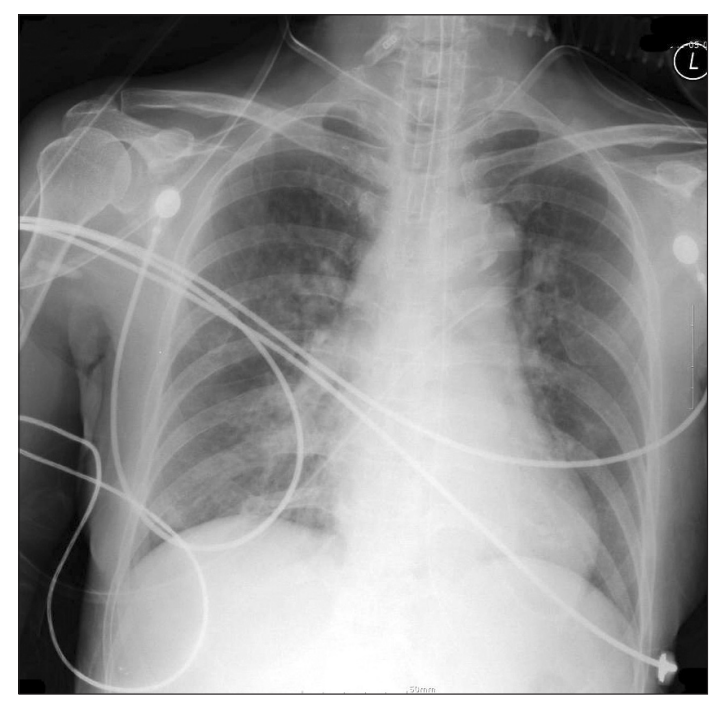

Fig. 2. Portable chest radiograph taken three days after surgery in the ICU shows near normal findings. 
enzyme studies and echocardiography were unremarkable. Extubation was attempted on the second postoperative day because her $\mathrm{SpO}_{2}$ remained at $100 \%$, her breathing was spontaneous, and her chest radiograph had improved (Fig. 2). Immediately after extubation, however, the patient became cyanotic and hypoxia developed and she was reintubated. According to the advice of our cardiologist colleagues, repeated echocardiography and coronary angiography was performed, which suggested transient stress-induced cardiomyopathy. Dobutamine $5 \mu \mathrm{g} / \mathrm{kg} / \mathrm{min}$ was infused. The patient was extubated successfully and weaned from the dobutamine infusion on the sixth postoperative day but still showed some degree of dyspnea on $3 \mathrm{~L} / \mathrm{min}$ via nasal cannula. Otolaryngology consultation attributed the residual dyspnea and the initial upper airway obstruction to bilateral vocal cord dysfunction. Given the possibility of sudden respiratory arrest, the patient underwent a tracheostomy.

\section{Discussion}

Negative pressure pulmonary edema can develop after an acute upper airway obstruction secondary to general anesthesia. Its incidence has been reported to be as high as $11 \%$ [4]. The most common cause of upper airway obstruction immediately after general anesthesia is laryngospasm [1], followed by an occluded endotracheal tube due to biting [5]. Initially, the primary cause of the pulmonary edema in this patient was attributed to an upper airway obstruction due to laryngospasm but the failure of repeated extubation suggested the primary cause to be vocal cord paralysis.

In our patient, the differential diagnosis of acute pulmonary edema included fluid overload, cardiogenic edema, neurogenic edema, acute lung injury, allergic reaction, and upper airway obstruction [4]. Fluid overload was unlikely, as a mere $900 \mathrm{ml}$ of lactated Ringer's solution had been administered over the three hour period. Initially, cardiogenic pulmonary edema was excluded due to the normal electrocardiography, cardiac enzymes, and echocardiography, even though the patient suffered transient stress-induced cardiomyopathy. An allergic reaction was also excluded based on the absence of rash, redness, or tissue swelling. Neither the clinical presentation nor chest radiograph provided evidence of aspiration. In addition, there was no evidence of central nervous system or lung injury during the perioperative period. On the other hand, the central nervous system depression and upper airway muscle relaxation associated with anesthesia or possibly with her antidepressant medication could have precipitated the upper airway obstruction after extubation [6].

A thyroidectomy is associated with several complications, most importantly hypocalcemia secondary to devascularization of the parathyroid gland. Significant hoarseness may also be caused by the recurrent laryngeal nerve injury [7]. In addition, the airway may be compromised by a wound hematoma or vocal cord paralysis. The recurrent laryngeal nerve arises from the vagus nerve and is a mixed motor, sensory, and autonomic nerve that innervates both the adductor and abductor muscles of the vocal cord. Unilateral injury, temporary or permanent, is classically described as a paralyzed vocal cord with a loss of movement from the midline [8]. The complication rate of thyroidectomy appears to be affected by the surgeon's experience. Most complications can be avoided by meticulous hemostasis at closing, which results in a $<1 \%$ complication rate [9]. An upper airway obstruction can occur with bilateral vocal cord paralysis [10]. Even unilateral vocal cord paralysis can obstruct the airway, impair swallowing and weaken the voice [11]. Similar to our case, Sánchez-Ortega et al. [12] reported a case of acute pulmonary edema in a 72-year-old woman with no significant prior medical history except for mild arterial hypertension. Her pulmonary edema was caused by an acute obstruction of the upper airway secondary to vocal cord paralysis that developed during the immediate postoperative phase after a thyroidectomy.

Several methods can be used to prevent and detect a recurrent laryngeal injury early [13]. Visual identification of the recurrent laryngeal nerve during thyroid surgery by the surgeon is recommended. Intraoperative neural monitoring can be performed by intraoperative visualization of the glottis by laryngoscope during surgery [14], laryngeal palpation during recurrent laryngeal nerve stimulation or the use of intramuscular electrodes to detect the laryngeal muscle electromyography (EMG) activity in response to recurrent laryngeal nerve stimulation.

As a risk minimization tool, intraoperative nerve monitoring (IONM) has been introduced to confirm recurrent laryngeal nerve function integrity intraoperatively [13]. A Xomed NIM II monitor (Medtronic Xomed, Jacksonville, Florida, USA) and Xomed NIM monitoring endotracheal tube with a surface EMG electrode was designed to rest on the luminal aspect of the bilateral true vocal cords. This system records the passive and evoked EMG monitoring of the thyroarytenoid laryngeal muscle during surgery. General anesthesia must be administered without muscle paralysis to enable EMG recording.

Negative pressure pulmonary edema normally resolves rapidly without aggressive treatment or invasive monitoring. Treatment consists of a variable regimen of diuretics, digoxin, corticosteroids, morphine and fluid restriction [3]. Willms and Shure [3] reported that mechanical ventilation, normally with PEEP, was used in $65 \%$ of all cases of pulmonary edema reviewed and in $55 \%$ of those cases due to laryngospasm. PEEP relieves pulmonary edema by decreasing venous return and 
preload in the pulmonary circulation. It also prevents airway closure during expiration [15].

The risk of a postoperative upper airway obstruction is high in cases in which the surgical field overlaps the patient's airway. This can easily lead to negative pressure pulmonary edema, even after the obstruction has been relieved. As this case demonstrates, anesthesiologists need to be vigilant to the possibility of an upper airway obstruction and resulting pulmonary edema during the postoperative period after a thyroidectomy.

\section{References}

1. Lang SA, Duncan PG, Shephard DA, Ha HC. Pulmonary oedema associated with airway obstruction. Can J Anaesth 1990; 37: 210-8.

2. Cascade PN, Alexander GD, Mackie DS. Negative pressure pulmonary edema after endotracheal intubation. Radiology 1993; 186: 671-5.

3. Willms D, Shure D. Pulmonary edema due to upper airway obstruction in adults. Chest 1988; 94: 1090-2.

4. Krodel DJ, Bittner EA, Abdulnour R, Brown R, Eikermann M. Case scenario: acute postoperative negative pressure pulmonary edema. Anesthesiology 2010; 113: 200-7.

5. Liu EH, Yih PS. Negative pressure pulmonary oedema caused by biting and endotracheal tube occlusion--a case for oropharyngeal airways. Singapore Med J 1999; 40: 174-5.

6. Mamiya H, Ichinohe T, Kaneko Y. Negative pressure pulmonary edema after oral and maxillofacial surgery. Anesth Prog 2009: 56: 49-52.

7. Mazzaferri EL, Kloos RT. Clinical review 128: Current approaches to primary therapy for papillary and follicular thyroid cancer. J Clin Endocrinol Metab 2001; 86: 1447-63.

8. Hartl DM, Travagli JP, Leboulleux S, Baudin E, Brasnu DF, Schulumberger $\mathrm{M}$. Clinical review: current concepts in the management of unilateral recurrent laryngeal nerve paralysis after thyroid surgery. J Clin Endocrinol Metab 2005; 90: 3084-8.

9. Zarnegar R, Brunaud L, Clark OH. Prevention, evaluation, and management of complications following thyroidectomy for thyroid carcinoma. Endocrinol Metab Clin North Am 2003; 32: 483-502.

10. San Luis Calo E, Ares Rodríguez X, Blanco Casais N, Masid Gómez A, Cortiñas Díaz J, Alvarez Escudero J. Utility of heliox during treatment of upper airway obstruction secondary to bilateral vocal cord paralysis after thyroidectomy. Rev Esp Anestesiol Reanim 2009; 56: 319-21.

11. Kashima HK. Documentation of upper airway obstruction in unilateral vocal cord paralysis: flow-volume loop studies in 43 subjects. Laryngoscope 1984; 94: 923-37.

12. Sánchez-Ortega JL, Carpintero-Moreno F, Olivares-López A, Borrás-Rubio E, Alvarez-López MJ, García-Izquierdo A. Acute pulmonary edema secondary to acute upper airway obstruction. Rev Esp Anestesiol Reanim 1992; 39 :34-6.

13. White WM, Randolph GW, Hartnick CJ, Cunningham MJ. Recurrent laryngeal nerve monitoring during thyroidectomy and related cervical procedures in the pediatric population. Arch Otolaryngol Head Neck Surg 2009; 135: 88-94.

14. Eltzschig HK, Posner M, Moore FD Jr. The use of readily available equipment in a simple method for intraoperative monitoring of recurrent laryngeal nerve function during thyroid surgery: initial experience with more than 300 cases. Arch Surg 2002; 137: 452-6.

15. Kamal RS. Agha S. Acute pulmonary oedema. A complication of upper airway obstruction. Anaesthesia 1984; 39: 464-7. 